\title{
NARRATIVAS, ARTE E CONTEMPORANEIDADE
}

\section{Apresentação}

As narrativas estão presentes em todos os tempos, lugares e sociedades. Pessoas e grupos criam suas narrativas e, frequentemente, compartilham-nas com sujeitos de diferentes culturas. Histórias são contadas de muitas formas, através de diversas mídias, ganhando sentido como representações que emergem e transitam por mitos, rituais, repertórios orais, visuais, musicais e cênicos, sendo emolduradas por práticas subjetivas e culturais que as transformam/qualificam como narrativas.

Temos assistido ao desenvolvimento, sem precedentes, de inúmeras modalidades de narrativas - orais, filosóficas, científicas, literárias, fotográficas, antropológicas, artísticas, educacionais, cinematográficas, videográficas, digitais, de publicidade, gestão, informação etc. A velocidade e o volume de narrativas que nos invadem e interpelam, cotidianamente, constituem uma avalanche, que nos encharca e consome, sem que tenhamos tempo suficiente para refletir, analisar, saber quem são os agentes da sua produção e as figuras da sua construção simbólica, ou, quais mecanismos de poder elas produzem e reproduzem. Além disso, as narrativas não obedecem a um formato, não se submetem à uma perspectiva ou crítica e tampouco se acomodam a modelos estabelecidos, situação que, muitas vezes, incomoda e intriga.

O valor epistemológico e existencial da experiência está ligado às narrativas como uma maneira de ensaiar, refletir e rememorar episódios, vivências e afetos, possibilitando outras visões de eventos e coisas, articulando práticas subjetivas do processo de investigação, com aprendizagens construídas ao longo da vida.
Do ponto de vista metodológico, a experiência demarca políticas de localização, de posicionamento ideológico, de contextos nos quais a parcialidade é condição para que as narrativas sejam tratadas como vestígios, pegadas da cultura nos nossos modos de ser, pensar, agir e sentir. As tecnologias digitais contribuíram de modo significativo não apenas para ampliar a produção de narrativas, mas, principalmente, para transportá-las, em tempo real, por meio de computadores, câmeras fotográficas e celulares, criando links e tornando-as públicas nas redes sociais.

Na esfera pública global dos meios de comunicação, as redes sociais e a crise da interpretação coincidem com o esgarçamento das práticas de discussão e análise dialética. A celebração da diversidade, a fetichização de particularismos e o narcisismo da identidade apontam para a necessidade de analisar as consequências políticas, teóricas e acadêmicas, que contribuíram para a desconstrução da hegemonia conceitual tal como praticada nas instituições educacionais do mundo ocidental.

A pós-modernidade, ou a lógica cultural e econômica do capitalismo, nos obrigou a reconhecer a transformação estrutural das diferentes formas de saber que carregaram no seu bojo as relações de poder internas ao sujeito e à construção da identidade, conforme detalha Foucault (1998)1. Hoje, as formas tradicionais de poder, anteriormente localizadas em instituições e pessoas, imiscuem-se nos softwares, em fibras óticas, nos provedo-

1 FOUCAULT, M. Microfísica do Poder. Por uma genealogia do poder; organização e tradução de Roberto Machado. 13a ed. Rio de Janeiro: Graal, 1998. 
res corporativos de Internet, criando modalidades de poder pós-representativas, que se manifestam pelo modo como organizam, desenham, configuram e, muitas vezes, embaralham o mundo em que vivemos. Estas condições sutis e "impessoais", e, portanto, não mais representativas dos sujeitos, produzem implicações que comprometem a disposição crítica, os gestos simbólicos e o posicionamento político, invadindo a vida cotidiana e deixando-a em suspensão, desconexa. Nesse sentido, "Narrativas, arte e contemporaneidade" é temática que incorpora ações - às vezes participativas, mas, com frequência, colaborativas - com o objetivo de elucidar a produção simbólica, seu impacto no tecido social e no cotidiano, mas, sobretudo, a sua importância na construção da subjetividade.

Processos criativos em dança são deflagrados na conjunção corpo-imagem-experiência -performatividade-espetáculo, transformando-se em potência da arte contemporânea, ao narrarem subjetividades, experiências e aprendizagens de corpos que profanam, estetizam e politizam imagens e artefatos visuais. No texto Danza la vida: narrativas de um processo criativo com imagens de Frida Kahlo, de Odailso Berté, perguntas cujas respostas são materializadas através de movimentos e gestualidades - como preconizava Pina Bausch - são a fagulha propulsora das ações desenvolvidas por alunos dançarinos do Laboratório Investigativo de Criações Contemporâneas em Dança (LICCDA) da Universidade Federal de Santa Maria, criando e investigando uma poética da dança contemporânea que se constrói a partir das imagens de Frida Kahlo.

$\mathrm{O}$ autor mostra como corpo, experiência e imagem são reterritorializados, via performance, ganhando status artístico e político, sendo compreendidos e apresentados como ações vitais para a aprendizagem de saberes sociais e culturais. Experiências e narrativas visuais de um corpo vivido, sofrido, kahlado e emocionalmente dilacerado, transcendem tempo e lugar, contribuindo para que a performance/dança se constitua, simultaneamente, como prática e metodologia interpretativa. Essa reconfiguração das subjetividades, da política e da estética, na vida cotidiana, nos coloca em sintonia com identidades e realidades sociais que instauram sentidos de legitimação das condições de criação e investigação, transformando a maneira como nos aproximamos e aderimos às narrativas artísticas contemporâneas.

Nesse contexto, as reconfigurações das subjetividades, da política e da estética são, ao mesmo tempo, pop e contemporâneas, conforme afirma o autor, porque "possibilitam refletir acerca da práxis sociocultural e política em torno das práticas e estéticas populares de uso, transformação e ressignificação de produtos e imagens...". Fenômenos e imagens contempop nos assediam cotidianamente, desafiando estratégias globais de controle e regulação das políticas educativas, pedindo passagem diante da relação cada vez mais intensa entre educação e economia, buscando tornar um pouco mais porosa a burocratização e, principalmente, a gestão do sistema educativo.

A relação intrínseca entre dança e narrativa, na qual "a narrativa pode ser enredo da dança e a dança pode ser uma narrativa", é o tema de Es(ins)critas do corpo dançante: narrativas singulares e plurais, proposto por Neila Cristina Baldi, no segundo artigo deste dossiê. Considerações históricas sobre a dança cênica, no mundo ocidental, inicialmente construída a partir de narrativas literárias, desvelam modos por meio dos quais a escrita de si pode fornecer combustivel para a performance, enquanto prática pedagógica, nos processos de formação de professores, desenhando movimentos e gestualidades corporais como uma maneira de pesquisar a criação coreográfica. 
Histórias de vida possibilitam interfaces entre o campo de estudos da dança e da pesquisa autobiográfica, abrindo espaço para reflexões sobre relações de afeto, subjetividade, retalhos de vivências corpográficas e experiência educativa. Como movimentos cotidianos, as narrativas de si geram deslocamentos cênicos, políticos e estéticos, ensejando o uso de práticas performativas do dia a dia que desaguam numa polifonia de vozes, identidades e composições cênicas, visando a emancipação dos corpos.

Tomando como exemplo a dança-teatro de Pina Bausch, ou sua modalidade de "autobiografia em cena", a autora descreve a ruptura de abordagens narrativas lineares que, gradativamente, se tornaram polissêmicas, ao dançar episódios coreográficos que contam histórias contemporâneas de sentimentos, conflitos, angústias, desejos, dissabores e amores, que se materializam através de fragmentos de memórias e de experiências vividas. Assim, dançarinos se descobrem como sujeitos que dançam, ao aprenderem a dançar, ao mesmo tempo em que aprendem enquanto dançam, vivendo uma sinergia que privilegia a diversidade de usos e experiências do cotidiano, valorizando práticas pedagógicas que incluem aspectos relacionados à subjetividade, à afetividade e à sensibilidade.

O texto seguinte, Reflexões em Torno de uma Formação em Animação Teatral, analisa questões institucionais e curriculares resultantes da experiência de criação do Curso de Mestrado em Animação Teatral, no Instituto de Educação da Universidade do Minho, Portugal. Uma agenda de discussão sobre o estado da Educação Artística em Portugal, associada a estudos científicos, relatórios oficiais e debates, em conferências e simpósios nacionais e internacionais, promovidos por agências europeias e entidades portuguesas, são iniciativas que produziram informação crítica e subsídios para a elaboração da proposta de criação do curso.

Segundo as autoras Maria Flor Dias e Carla Pires Antunes, o curso busca responder, através da pesquisa em arte e, mais especificamente, por meio da animação teatral na formação superior e em nível de pós-graduação, a desafios do mundo contemporâneo decorrentes do surgimento de demandas geradas pelas novas "comunidades criativas" e também pelas "culturas juvenis" e as socializações que caracterizam suas performances cotidianas. Essas culturas performativas emergem em espaços de dissidência, fluidos, descontínuos, inconstantes, como uma maneira de reagir a enquadramentos prescritivos que a sociedade e as instituições educacionais insistem em manter. Tais movimentos e oscilações são acompanhados por um sentimento de impetuosidade que oferece, mesmo que temporariamente, uma sensação de mobilidade.

A estrutura conceitual do curso de mestrado tem como foco a inovação associada à produção de conhecimento visando uma formação em pesquisa ancorada em princípios teórico-metodológicos que envolvem autonomia, flexibilidade e abordagens colaborativas. Nas Unidades Curriculares Obrigatórias, as disciplinas Estudos Performativos I e II sinalizam para a necessidade de ir além dos limites da academia e suas lógicas, priorizando experiências vividas, encarnadas, e o modo como os sujeitos pesquisadores negociam práticas de subjetividade-subjetivação. Ganha destaque nas Unidades Curriculares Opcionais a preocupação em deslocar o foco de abordagens conceituais representacionais - hegemonia da linguagem e da significação das práticas discursivas - para processos materiais e culturais de produção de conhecimento. Reterritorializações disciplinares, desconstrução teatral, democratização cultural e a diversificação de contextos, que incluem poéticas sociais e 
culturas do fazer, são ideias que nortearam a construção curricular do curso.

Trazendo um recorte da sua tese de doutorado, o texto Narrativas autobiográficas: entre lembranças, experiências e artefatos, de Luiz Carlos Pinheiro Ferreira, explicita o caráter dialógico e relacional do conhecimento autobiográfico, ao nos conduzir por um itinerário de percepções, sentimentos, experiências e artefatos que mapeiam temporalidades e lugares articulados a partir de retalhos do vivido, rememorações, fragmentos e episódios que se entrecruzam e são transformados em objetos do pensamento. Utilizando arquivos pessoais e familiares, o autor explora e desbrava trilhas esquecidas/apagadas da existência, confrontando dores simbólicas que se manifestam em agruras do corpo, esgarçam dimensões subjetivas, estéticas, e provocam uma "escavação arqueológica de si".

Os fragmentos narrativos que compõem o texto geram movimentos afetivos e metafóricos, intensificam processos reflexivos, ao mesmo tempo que revisitam pegadas tênues de diferentes tempos e espaços, rememorando episódios de uma infância longínqua, vivida numa cidade do interior. Arte e profissão docente descendem dessas experiências familiares e se miscigenam, como uma força subjetiva dissimulada, porém, invasiva, materializandose na forma de um acordeão, instrumento/ artefato ícone, que reúne lembranças, revive ambientes e ambiências festivas, jorrando pelas brechas do passado pixels de um cotidiano de afetos, intuições, sensibilidades, aprendizagens e subjetividades.

Retalhos de uma colcha, aparentemente assimétricos e desconectados, costuram lembranças da avó materna, mas também condensam fragmentos, lembranças, experiências e texturas afetivas que autenticam relações dialógicas com o mundo, com os alunos, com a pesquisa, com a docência e consigo mesmo.
Confrontados, esses retalhos ganham unidade a partir da diferença. Criam artesania e autonomia conceitual-metodológica, propiciando uma bricolagem de questões estéticas, políticas e pedagógicas que desafiam os regimes de poder que sitiam as instituições educacionais e as narrativas docentes.

Reconstruir experiências marcantes, significativas ou formadoras, é uma maneira de criar espaços de interpretação através de reencontros com a própria vida. É também uma maneira de obter permissão para pesquisar arquivos pessoais, ouvir relatos, estudar e compreender os sonhos, projetos e expectativas de outras pessoas, possibilitando encontros com o passado, com trajetórias, itinerários e memórias que ensejam reflexões sobre histórias de vida. Assim o fazem Paulo Passos e Raimundo Martins, no artigo O cineasta sertanejo Josafá Duarte: narrativas de vida e obra no contexto contemporâneo, ao biografarem episódios/momentos dos caminhos percorridos por Josafá Duarte, o cineasta sertanejo que vive em Salgado dos Mendes, município de Forquilha, norte do Ceará. O cineasta já finalizou 23 filmes de ficção, entre curtas, médias e longas-metragens.

Homem simples, filiado ao Sindicato dos Trabalhadores Rurais, Josafá Duarte participou de ocupações, ajudou a assentar famílias em terras improdutivas e sentiu na pele o medo diante da ameaça de morte feita por fazendeiros poderosos da região. Uma câmera emprestada, muitas ideias na cabeça e a disposição da comunidade de participar do processo cinematográfico foram os ingredientes necessários para fazer surgir o Cinecordel. As cópias das suas produções, após serem lançadas em espaços públicos da comunidade, são multiplicadas e vendidas a preço de custo, por camelôs, em bancas de revistas de Sobral, Fortaleza, e em outros estados como Tocantins, Maranhão, Piauí e Pernambuco. 
Sujeitos produtores de cultura e fazedores de cinema surgem como parte do arrastão pós-moderno que trouxe, em uma de suas vertentes, um enorme salto tecnológico-digital. Além do impacto irreversivel no regime de visualidades contemporâneo - invasão e alteração dos modos de perceber, sentir e processar a vida cotidiana, ruptura da aura e desmistificação da "obra" de arte -, o barateamento do custo de equipamentos como videocâmaras, computadores e softwares para a edição de imagens possibilitou que pessoas, sem treinamento técnico ou formal na área, encontrassem formas de participar e produzir cultura. Essa proliferação de imagens possibilitou, também, um deslocamento da percepção de ideologia e identidade de sujeitos contemporâneos durante muito tempo alijados das esferas pretensamente autônomas da arte, da cultura e da educação.

O Centro de Pesquisa e Valorização da Cultura Bororo, hoje denominado Museu Comunitário Bororo e Centro de Cultura Pe. Rodolfo Lunkenbein, na aldeia Meruri, Mato Grosso do Sul, é o eixo de um enredo narrado por Aivone Carvalho, pesquisadora responsável, num primeiro momento, pela "repatriação visual" de documentação fotográfica e, posteriormente, pela "repatriação concreta" de objetos da comunidade indígena Bororo, do Museo Missionario Etnologico Colle Don Bosco, na Itália, para o Brasil. No decorrer da narrativa, a ela se associam, primeiro, Paulinho Ecerae Kadojeba, cinegrafista, protagonista e parceiro na construção dos espaços que hoje constituem a "casa central", a Sala de Expressão de Cultura e as "vitrines clânicas" do Museu Comunitário de Meruri e, segundo, o antropólogo José da Silva Ribeiro, docente da Universidade Aberta de Lisboa e pesquisador visitante, no Programa de Pós-graduação em Arte e Cultura Visual da Universidade Federal de Goiás, com significativas reflexões apresentadas no texto Narrativa dialógica de um cinegrafista indigena.

A narrativa descreve as novas formas de expografia utilizadas na exposição dos objetos étnicos no Museu Comunitário resultado de concepções e deslocamentos estéticos vinculados à articulações de caráter pedagógico feitas com professores e alunos da escola da aldeia através de cursos, oficinas e trabalhos colaborativos que têm como marca abordagens participativas, ou seja, a utilização de objetos que estão expostos no museu, pela comunidade. A transição de uma sociedade oralizada para uma sociedade alfabética, consequência da "missão" ou visão "catequética" dos padres salesianos, ofereceu aos bororos a possibilidade de unir oralidade e iconografia, modos de expressão complementares que potencializaram reflexões sobre ecoformação cultural, aprendizagens experienciais e, sobretudo, sobre seus universos imaginários e narrativas míticas.

As produções videográficas de Paulinho são a culminância de esforços conjugados, com apoios da FUNAI, da UNESCO, da Rede Globo, ainda que indiretamente e, posteriormente, da TV Centro América. A curiosidade de aprender e o trabalho como ajudante, na filmagem de rituais, funerais e danças da comunidade, foi a senha para receber promessas de cursos a serem realizados com membros das equipes de filmagem, promessas que nunca se efetivaram. Uma minicâmera trazida da Itália, presente da professora Aivone Carvalho, marca o reinício da trajetória autodidata de Paulinho como cinegrafista. A filmagem do funeral da esposa do ancião Meriri Ekureu funcionou como obra de estreia do cineasta. Após vários dias de trabaIho intenso e cansativo, Paulinho foi convidado para fazer a edição do seu documentário, no estúdio de produção e audiovisual da Universidade Católica Dom Bosco, em Campo Grande. Como ele mesmo diz, esse seria "o desfecho 
do meu sonho em me retratar com minha comunidade, mostrando que era possivel fazer um documentário que não ferisse nossos segredos".

Visualidades centradas em biografias ou testemunhos educativos são terrenos férteis para revisitar momentos da historicidade e subjetividade de sujeitos docentes, motivando-os a refletir sobre suas trajetórias e processos de aprendizagem. Conversar, escrever e comentar essas experiências é uma maneira de tornar públicos aspectos críticos de vivências que acontecem em espaços institucionais e, com frequência, passam a compor o repertório narrativo de seus agentes/protagonistas. Este exercício de relatar e refletir "sobre visualidades construídas no uso das tecnologias e meios contemporâneos a partir de pequenos episódios" da própria biografia é o foco do artigo Narrativas autobiográficas e visualidade: entre a academia, a tecnologia e a paternidade, de Fernando Miranda.

Muitas são as maneiras de ser professor, pai, colega, irmão, assim como também são múltiplos os modos de vincular experiência individual a contextos sociais, familiares e profissionais. Tomando esse tema como mote, o autor descreve seus estranhamentos e aprendizagens quando, por um período de 6 meses, ao realizar pós-doutoramento no Programa de Pós-graduação em Arte e Cultura Visual, na Universidade Federal de Goiás, conheceu a experiência de viver a mais de mil quilômetros de distância de sua cidade, Montevidéu-Uruguai, de sua esposa, Paola, e de sua filha Maite, à época com apenas sete anos. A percepção de distância e de tempo incidia de forma potente sobre a pequena Maite, gerando estresse e angústia para os pais, e insônia para a filha. A proposta de um jogo de imagens e palavras narrando coisas e episódios do cotidiano, construído durante o dia e enviado por WhatsApp, associado à história que era contada todas as noites via internet, funcionou como um tranquilizante que a fazia dormir. Graças à tecnologia e aos recursos digitais on-line, a pequena Maite e seu pai construíram uma rotina que, apesar da distância, os aproximava por imagens e via redes sociais.

Investigando práticas de subjetividades das identidades nas redes sociais, Carla Abreu apresenta um texto - Narrativas digifeministas: arte, ativismo e posicionamentos políticos na internet - que articula marcas das políticas da sexualidade a ações feministas e produções artísticas digifeministas. Ao questionar a separação ontológica dos contextos on-line e off-line, a autora demonstra como as relações desiguais de poder se mantêm, a despeito da crença de que as tecnologias transformariam esta condição. Os conceitos de ciberfeminismo e digifeminismo são amplamente explorados e exemplificados, trazendo para os leitores uma compreensão expandida das iniciativas sociais, políticas e artísticas, de jovens mulheres na internet.

As reflexões de Carla Abreu provocam um adensamento de questões em torno de estratégias de oposição feminista aos códigos normativos, hegemonia e opressões ao corpo, voz e ações, criadas e divulgadas no ciberespaço. Segundo a autora, os inúmeros grupos ou indivíduos que protagonizavam (e protagonizam) este ativismo feminista "compartilhavam o desejo de justiça social, maior empoderamento e envolvimento das mulheres nas lutas políticas para combater o modelo heteropatriarcal". Analisando a história do ciberfeminismo e criticando a euforia inicial acerca das oportunidades das redes digitais, Carla Abreu pontua as rupturas teóricas e práticas no campo, acoIhendo em suas investigações as contribuições de pesquisadoras e artistas de várias partes do mundo ocidental.

Através de imagens de trabalhos de artistas digifeministas, com este texto, somos levados 
a pensar nos encontros entre arte, ativismo e feminismos - plurais e contrários a definições totalizantes - reunidos em posicionamentos e produções, também diversificados, nos quais as diferentes tentativas de ameaça e subordinação das subjetividades femininas são contestadas, denunciadas, reconfiguradas. O cuidadoso olhar de Carla de Abreu fala de experiências dinâmicas que objetivam criticar e criar agenciamentos políticos para romper com relações de poder e saber, normalizados e normalizadores.

O texto Bonecos, robôs, narcisos e fetiches: o esquecimento de si e a desumanização do outro, de Pablo Petit Sérvio, também tem como centro as chamadas tecnologias digitais, mais especificamente as redes sociais, porém, discutindo e propondo uma vertente educativa para lidar com a subjetividade fetichista e narcisista que pode ser vista na web. Engajado numa pesquisa deflagrada pelo contato com o “desconcertante anúncio 'loverobots' (2006)2, da marca Melissa de calçados plásticos femininos", conforme descreve o autor, muitas perguntas se alinham para refletir sobre a imagem do corpo e sua importância em nossas vidas.

Partindo da noção de indivíduo e das marcas que registraram mudanças nas concepções contemporâneas sobre o tema, Pablo aproxima-se de variadas imagens, de origens e épocas diferenciadas, para mostrar como vemos e como nos vemos, estabelecendo relações entre afetos, experiências visuais e subjetividades. Neste sentido, o texto problematiza questões referentes à cultura da vaidade e da autoimagem, para proceder a argumentos críticos sobre a sociedade de consumo. Imagem, fetichismo e vaidade podem influenciar de forma significativa as experiências subjetivas dos sujeitos contemporâneos, representando uma tentativa de consolidar vivências frágeis, pro-

2 Anúncios Melissa Loverobots (2006). Fonte: Disponível em: <http://www.mirofotografo.com.br/post.php?id_ post $=37 \&$ cat $=\&$ subcat=3 $>$. Acesso em: 07 fev. 2017. visórias, voláteis. O corpo, como lócus afetivo e social, encarna expectativas de aconchego, segurança e liberdade que, associadas à necessidade de pertencimento, constituem o paradoxo de comunidades estéticas que buscam sustentação nas imagens das indústrias da publicidade e do entretenimento.

Diante de situações e contextos cada vez mais sedutores e complexos, as narrativas contemporâneas da arte passaram a explorar diferentes formas de organização colaborativa, entendendo a audiência como um tipo de comunidade cuja agenda propõe soluções provisórias que se fundamentam no princípio de que a arte deve ser "usada" e não mais "contemplada". Em sintonia com esses princípios, as narrativas contemporâneas passaram a ter um caráter participativo, dialógico, experimentando outros modelos de organização social e política que emergem da fragmentação, alienação e, em alguma medida, da deterioração do tecido social. A reconfiguração das relações sociais, decorrente da globalização e de seus processos de competitividade, migração, desestruturação do tempo e do espaço etc., evidencia práticas nas quais a arte se transforma em atividade que interpenetra o mundo, transversalmente, através de fugas, escapes e enlaces com outras disciplinas, dispositivos e regimes, no intuito de responder/atender a preocupações sociopolíticas.

Esse quadro geral de sintomas reflete o fato de que vivemos em uma cultura narrativa na qual afeto e subjetividade se deslocaram para o centro da esfera pública. 0 desejo coletivo de espaços de expressão e manifestações afetivas aspira revogar subjetividades privilegiadas, criando uma moldura para relatos, descrições e dispositivos que não são excepcionais, mas associam atores do mundo das artes a projetos que visam a ação política e social. Ao invocar subjetividades, esses atores abrem espaço para articular reflexão, ação po- 
lítica e lutas de poder, gerando agenciamentos vinculados a movimentos sociais, a coletivos autônomos e meios alternativos de comunicação e interação.

O dossiê Narrativas, arte e contemporaneidade propõe-se a acionar um espaço de autorreflexão que envolve diferentes aspectos dos processos globais de informação, conhecimento e educação - individuais, coletivos, institucionais, acadêmicos, artísticos, econômicos, sociais - apresentando narrativas que discutem formação teatral, formação em dança, docência e paternidade, cinegrafia sertaneja, indígena, autobiografia, cultura visual, digifeminismo e estéticas politizadas. Disseminadas ardilosamente via objetos, artefatos e práticas cotidianas, hoje, imagens de informação, de ficção, filmicas, de arte, de publicidade operam num modo silencioso, imiscuindo-se na ordem das coisas, dissimulando a maneira como são concebidas, produzidas e difundidas.

Impregnados pela curiosidade e pulsão que nos move, partilhamos com os leitores da Revista Brasileira de Pesquisa (Auto)biográfica os textos e reflexões deste dossiê.

Goiânia, abril de 2017

Raimundo Martins

Universidade Federal de Goiás

José da Silva Ribeiro Universidade Aberta de Lisboa Universidade Federal de Goiás 